\title{
Sugarcane transgenics expressing MYB transcription factors show improved glucose release
}

\author{
Charleson R. Poovaiah', William P. Bewg², Wu Lan ${ }^{3,4}$, John Ralph ${ }^{3,5}$ and Heather D. Coleman ${ }^{1 *}$ (1)
}

\begin{abstract}
Background: Sugarcane, a tropical C4 perennial crop, is capable of producing 30-100 tons or more of biomass per hectare annually. The lignocellulosic residue remaining after sugar extraction is currently underutilized and can provide a significant source of biomass for the production of second-generation bioethanol.

Results: MYB31 and MYB42 were cloned from maize and expressed in sugarcane with and without the UTR sequences. The cloned sequences were 98 and $99 \%$ identical to the published nucleotide sequences. The inclusion of the UTR sequences did not affect any of the parameters tested. There was little difference in plant height and the number of internodes of the MYB-overexpressing sugarcane plants when compared with controls. MYB transgene expression determined by qPCR exhibited continued expression in young and maturing internodes. MYB31 downregulated more genes within the lignin biosynthetic pathway than MYB42. MYB31 and MYB42 expression resulted in decreased lignin content in some lines. All MYB42 plants further analyzed showed significant increases in glucose release by enzymatic hydrolysis in $72 \mathrm{~h}$, whereas only two MYB31 plants released more glucose than control plants. This correlated directly with a significant decrease in acid-insoluble lignin. Soluble sucrose content of the MYB42 transgenic plants did not vary compared to control plants.
\end{abstract}

Conclusions: This study demonstrates the use of MYB transcription factors to improve the production of bioethanol from sugarcane bagasse remaining after sugar extraction.

Keywords: Sugarcane bagasse, Bioethanol, Biofuel, Lignin modification

\section{Background}

Sugarcane (Saccharum spp. Hybrids) is a C4 perennial crop grown in tropical and subtropical climates that is capable of producing large amounts of dry biomass per hectare annually [1]. It has a high capacity to convert light energy to biomass, which, along with efficient water and nitrogen use, makes it suitable to be grown in marginal land areas [2,3]. Although best known for accumulating and storing high concentrations of sucrose in its stem, and its use for sugar production, sugarcane also produces abundant lignocellulosic residues that remain after sugar extraction. This material is currently underutilized, but

\footnotetext{
*Correspondence: hcoleman@syr.edu

1 Department of Biology, Syracuse University, Syracuse, NY 13244, USA Full list of author information is available at the end of the article
}

holds the potential to act as a renewable source for biofuel production [4].

One of the main constraints in the production of biofuels is recalcitrance of feedstocks to enzymatic hydrolysis [5]. Lignin, a major component of the secondary cell wall, imparts mechanical support to the plant, enhances water transport, and protects the plants against pathogens [6], but at the same time acts as a barrier in the extraction of fermentable sugars from the lignocellulosic biomass due to its ability to resist degradation. Lignin is synthesized through the phenylpropanoid pathway by the oxidative polymerization of the monolignols $-p$-coumaryl, coniferyl and sinapyl alcohols. The resulting units of monolignol, when incorporated into the lignin polymer, are called $p$-hydroxyphenyl $(\mathrm{H})$, guaiacyl $(\mathrm{G})$ and syringyl (S) subunits, respectively [6, 7]. Pretreatment steps to 
remove lignin lead to the formation of compounds that inhibit saccharification and fermentation [5].

Lignin biosynthesis is regulated by the action of different transcription factors, including members of the R2-R3 MYB transcription factor family [8]. These transcription factors bind to the $\mathrm{AC}$ elements in the promoters of lignin biosynthetic genes and drive xylem-specific expression [9]. Among these transcription factors are $Z m M Y B 31$ and ZmMYB42, both of which are involved in the regulation of lignin biosynthesis in Zea mays. Expression of ZmMYB31 and ZmMYB42 independently in Arabidopsis resulted in reduced expression of lignin biosynthetic genes and led to a significant decrease in lignin content [10-12]. This resulted in greater release of fermentable sugars during enzymatic hydrolysis from the transgenics when compared with controls $[10,11$, 13]. Recent research found that the overexpression of $P v M Y B 4$ in switchgrass reduced lignin content through the downregulation of lignin biosynthetic genes, which in turn increased the saccharification of these plants threefold [14, 15]. Phylogenetic analysis of $P v M Y B 4$ showed that it was more closely related to $Z m M Y B 31, Z m M Y B 42$ and $Z m M Y B 38$ than the other MYB transcription factors comprising subgroup G4 $[11,16]$.

In this report, ZmMYB31 and ZmMYB42 were overexpressed in sugarcane to emulate previous findings [10-12] and to improve saccharification, as this characteristic would benefit the production of second-generation bioethanol from, and increase the monetary value of, sugarcane bagasse.

\section{Results}

\section{Alignment of cloned $Z m M Y B 31$ and $Z m M Y B 42$ sequences}

$Z m M Y B 31$ and $Z m M Y B 42$ were cloned from maize and transformed into sugarcane under the control of a maize ubiquitin promoter. There was $99 \%$ identity between the published MYB31 sequence and the cloned sequence for both nucleotide and protein sequences, whereas the published MYB42 sequence and the cloned sequences had $98 \%$ nucleotide identity and $99 \%$ protein identity (see Additional file 1 for nucleotide and amino acid sequence alignment). There was $100 \%$ amino acid sequence identity of the R2 and R3 domains between the cloned maize MYB31 and MYB42 genes and published sequences [12]. There were few differences in amino acid sequence within the C-terminal end of the translated MYB31 and MYB42 proteins and also in the nucleotide sequences of the $5^{\prime}$ and $3^{\prime}$ UTR sequences between cloned and published MYB31 sequences (see Additional file 1).

\section{Phenotype of MYB plants}

Seven lines were generated for each of the four constructs. Additionally, GFP was cloned in place of $M Y B$ in the same vector and the plants generated used as transgenic controls. Plants were confirmed as harboring the transgene of interest before being transferred to the greenhouse. Following 9 months of growth, the plants were harvested for analysis. Phenotypic measurements, including plant height, number of internodes, internode diameter of the third internode, and average internode length were determined at the time of harvest (Table 1). A $z$ score was calculated based on the average results of the GFP transgenic control plants. Any MYB plant with a $z$ score greater than 2 or less than -2 , indicating more than two standard deviations from the control group average, was considered to be different from controls. Overall, there was little difference in the height or number of internodes relative to controls and, in general, any changes seen in internode length were offset by changes in the number of internodes. MYB31ORF 7 was taller than controls and MYB42UTR 30 was shorter. MYB3ORF 2 was the only plant with a significant change in internode number, having fewer than the GFP control group (Table 1).

Most of the MYB ORF and UTR plants had smaller internode diameters. Of the MYB31ORF lines, except MYB31ORF 11, all other lines had significantly smaller diameter than the control plants. Among the MYB31UTR lines, MYB31UTR 7 had significantly larger diameter than the control plants (Table 1 ). The majority of the MYB31ORF lines had significantly longer internodes, whereas four lines of MYB31UTR had increased internode length. Of the MYB42 plants, two had larger internode diameters and four had smaller diameters. Similar results were seen for internode length, as four MYB42 plants had increased internode length and two had decreased length (Table 1).

\section{Quantitative PCR analysis of lignin biosynthetic pathway genes in MYB-expressing sugarcane}

Quantitative PCR analysis was performed on cDNA synthesized from leaf and young and maturing sugarcane internodes for each transgenic plant along with corresponding GFP transgenic controls. The plants were initially analyzed for expression of the transgenes in the leaves (prior to being transferred to the greenhouse) to confirm the presence of the transgene. Subsequently, qPCR was performed on cDNA synthesized from young and maturing sugarcane internodes (following 9 months of greenhouse growth) for each control and transgenic plant. The majority of MYB31 and MYB42 plants continued to express the MYB transgene in both young and maturing internode tissues (Fig. 1; see Additional file 2), although the levels of expression for some plants, MYB31UTR11 and MYB42UTR16 for example, were very low. Of the plants with no 
Table 1 Phenotypic measurements of MYB-expressing sugarcane

\begin{tabular}{|c|c|c|c|c|c|c|c|c|}
\hline \multirow{2}{*}{$\begin{array}{l}\text { Plant } \\
\text { GFP }\end{array}$} & \multicolumn{2}{|l|}{ Height (cm) } & \multicolumn{2}{|c|}{$\begin{array}{l}\text { Total number of } \\
\text { internodes }\end{array}$} & \multicolumn{2}{|c|}{$\begin{array}{l}\text { Third internode } \\
\text { diameter }(\mathrm{mm})\end{array}$} & \multicolumn{2}{|c|}{$\begin{array}{l}\text { Average internode } \\
\text { length }(\mathrm{cm})\end{array}$} \\
\hline & $129 \pm 24.26$ & & $15=$ & & 14.18 & & $8.56 \pm$ & \\
\hline & & z score & & z score & & z score & & z score \\
\hline \multicolumn{9}{|c|}{ MYB31ORF } \\
\hline 13 & 114 & -0.62 & 14 & -0.46 & 12.00 & -5.99 & 8.14 & -0.7 \\
\hline 11 & 132 & 0.12 & 13 & -0.93 & 14.29 & 0.29 & 10.15 & 2.63 \\
\hline 2 & 100 & -1.20 & 10 & -2.31 & 11.63 & -7.00 & 10.00 & 2.38 \\
\hline 7 & 205 & 3.13 & 15 & 0.00 & 12.93 & -3.44 & 13.67 & 8.45 \\
\hline 1 & 140 & 0.45 & 14 & -0.46 & 8.76 & -14.87 & 10.00 & 2.38 \\
\hline 8 & 158 & 1.20 & 14 & -0.46 & 12.45 & -4.75 & 11.29 & 4.51 \\
\hline 9 & 159 & 1.24 & 15 & 0.00 & 11.16 & -8.29 & 10.60 & 3.37 \\
\hline \multicolumn{9}{|c|}{ MYB31UTR } \\
\hline 27 & 140 & 0.45 & 16 & 0.46 & 12.57 & -4.42 & 8.75 & 0.31 \\
\hline 2 & 128 & -0.04 & 13 & -0.93 & 11.76 & -6.65 & 9.85 & 2.12 \\
\hline 18 & 131 & 0.08 & 13 & -0.93 & 14.45 & 0.73 & 10.08 & 2.51 \\
\hline 11 & 160 & 1.28 & 15 & 0.00 & 12.45 & -4.75 & 10.67 & 3.48 \\
\hline 12 & 147 & 0.74 & 14 & -0.46 & 11.80 & -6.54 & 10.50 & 3.21 \\
\hline 7 & 136 & 0.29 & 15 & 0.00 & 15.27 & 2.98 & 9.07 & 0.83 \\
\hline 20 & 108 & -0.87 & 15 & 0.00 & 12.79 & -3.82 & 7.20 & -2.26 \\
\hline \multicolumn{9}{|c|}{ MYB42ORF } \\
\hline 14 & 162 & 1.36 & 17 & 0.93 & 13.52 & -1.82 & 9.53 & 1.6 \\
\hline 16 & 130 & 0.04 & 17 & 0.93 & 17.28 & 8.49 & 7.65 & -1.52 \\
\hline 23 & 134 & 0.21 & 15 & 0.00 & 14.39 & 0.57 & 8.93 & 0.61 \\
\hline 11 & 138 & 0.37 & 15 & 0.00 & 11.04 & -8.62 & 9.20 & 1.05 \\
\hline 18 & 124 & -0.21 & 14 & -0.46 & 11.64 & -6.98 & 8.86 & 0.49 \\
\hline 21 & 163 & 1.40 & 16 & 0.46 & 12.18 & -5.49 & 10.19 & 2.69 \\
\hline 26 & 145 & 0.66 & 13 & -0.93 & 15.07 & 2.43 & 11.15 & 4.29 \\
\hline \multicolumn{9}{|c|}{ MYB42UTR } \\
\hline 28 & 92 & -1.52 & 12 & -1.39 & 14.00 & -0.50 & 7.67 & -1.49 \\
\hline 6 & 109 & -0.82 & 15 & 0.00 & 10.97 & -8.81 & 7.27 & -2.15 \\
\hline 32 & 137 & 0.33 & 14 & -0.46 & 16.10 & 5.26 & 9.79 & 2.02 \\
\hline 30 & 71 & -2.39 & 11 & -1.85 & 12.56 & -4.45 & 6.45 & -3.5 \\
\hline 15 & 147 & 0.74 & 15 & 0.00 & 16.34 & 5.91 & 9.80 & 2.05 \\
\hline 26 & 174 & 1.85 & 18 & 1.39 & 14.65 & 1.28 & 9.67 & 1.83 \\
\hline 16 & 162 & 1.36 & 17 & 0.93 & 13.41 & -2.12 & 9.53 & 1.6 \\
\hline
\end{tabular}

Overall averages for control ( $n=3$ individual plants) measurements are presented with standard deviation. $Z$ scores represent the number of standard deviations that each MYB plant is from the control average, with $z$ scores greater than 2 or -2 highlighted in italicized font. As phenotypic measurements could only be made once per transgenic plant, the number of standard deviations ( $z$ scores) for each MYB plant measurement were calculated against the transgenic controls. Plants are listed in ascending order of total lignin content

detectable $M Y B$ expression, it appears that this was only in young tissue and expression was detected in the maturing tissue of the same plants. In general, there also appeared to be a trend of increased $M Y B$ transgene expression in maturing tissue when compared with young tissue in all lines. No transgene expression was detected in any tissue of any GFP control plant. After confirming the $M Y B$ transgene expression level, the expression levels of lignin biosynthetic genes were quantified by qPCR from the same cDNA samples
(Fig. 2). See Additional file 3 for qPCR of all lines and statistical analysis.

$\mathrm{C} 4 \mathrm{H}$ was the only gene significantly downregulated in all the events of MYB31 and MYB42 in the young internodes. In MYB31ORF plants, most of the lignin biosynthetic genes were significantly downregulated in the leaf, whereas in MYB31UTR plants, only $\mathrm{C} 3 \mathrm{H}$ and COMT were significantly downregulated in leaf tissue. In young internodes, $\mathrm{C} 3 \mathrm{H}, 4 \mathrm{CL}, \mathrm{F} 5 \mathrm{H}$ and $\mathrm{COMT}$ were significantly downregulated in MYB31ORF, whereas in MYB32UTR 

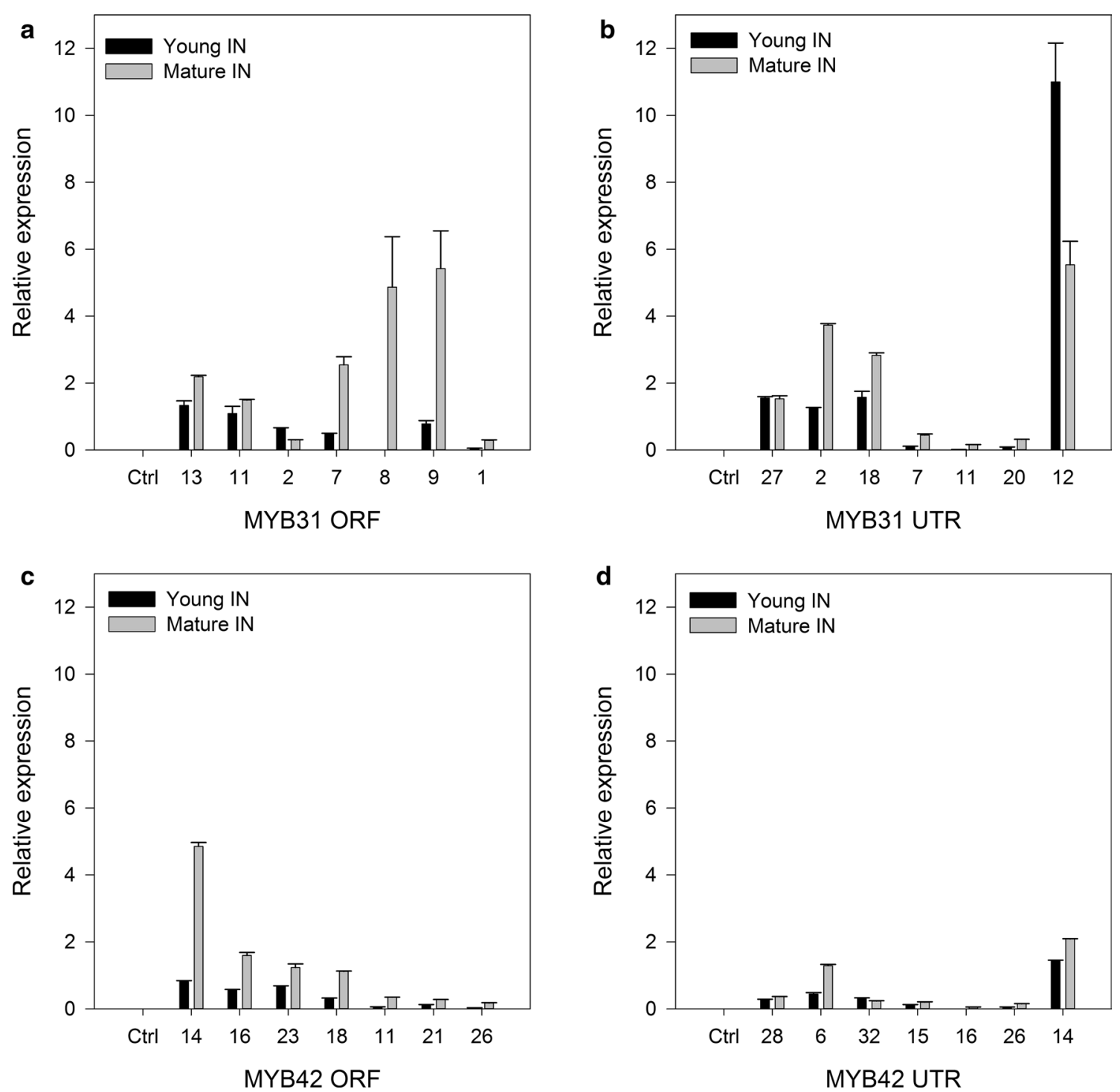

Fig. 1 Quantitative expression of MYB32 and MYB42 in transgenic sugarcane. Quantitative PCR $\triangle C t$ values showing standard error of the mean of a MYB31ORF, b MYB31UTR, c MYB42ORF and $\mathbf{d}$ MYB42UTR expression in the MYB-transformed sugarcane plants after qPCR analysis of young and maturing internode tissues post-harvest. Each sample underwent qPCR in triplicate. Plants are listed in ascending total lignin content for each line. Control $n=3$

only $\mathrm{C} 3 \mathrm{H}$ was significantly different. In maturing internodes, $\mathrm{C} 3 \mathrm{H}$ and $\mathrm{F} 5 \mathrm{H}$ were significantly decreased in MYB31ORF. In MYB42 plants, MYB42ORF downregulated $\mathrm{C} 3 \mathrm{H}, \mathrm{F} 5 \mathrm{H}$ and $4 \mathrm{CL}$ in young internodes of most plants, whereas MYB42UTR downregulated only $\mathrm{C} 3 \mathrm{H}$ in young internodes. MYB42 also upregulated $P A L$ and $C A D$ gene expression in internodes.

The overall trends suggest that $Z m M Y B 31$ downregulated more genes than $Z m M Y B 42$ when constitutively expressed in sugarcane (Fig. 2). See Additional file 3 for data on all lines and statistical analysis. Plants expressing MYB31 had a downregulatory pattern which is spread across genes that are both early and late in the lignin biosynthesis pathway, whereas MYB42 expression appeared to downregulate the early pathway genes, with the exception of $P A L$, more than the later pathway genes (Fig. 2; see Additional file 3). In common, both $M Y B$ genes downregulated $\mathrm{C} 4 \mathrm{H}$ and exhibited an increase in $P A L$ and $C A D$ expression. Although not seen in MYB31 plants, MYB42 plants also showed increases in CCoAOMT, $C C R$ and $C O M T$ expression. As well as downregulating more genes of the lignin biosynthetic pathway overall, MYB31 also appeared to be more consistent in gene regulation across the different tissue types when compared with 


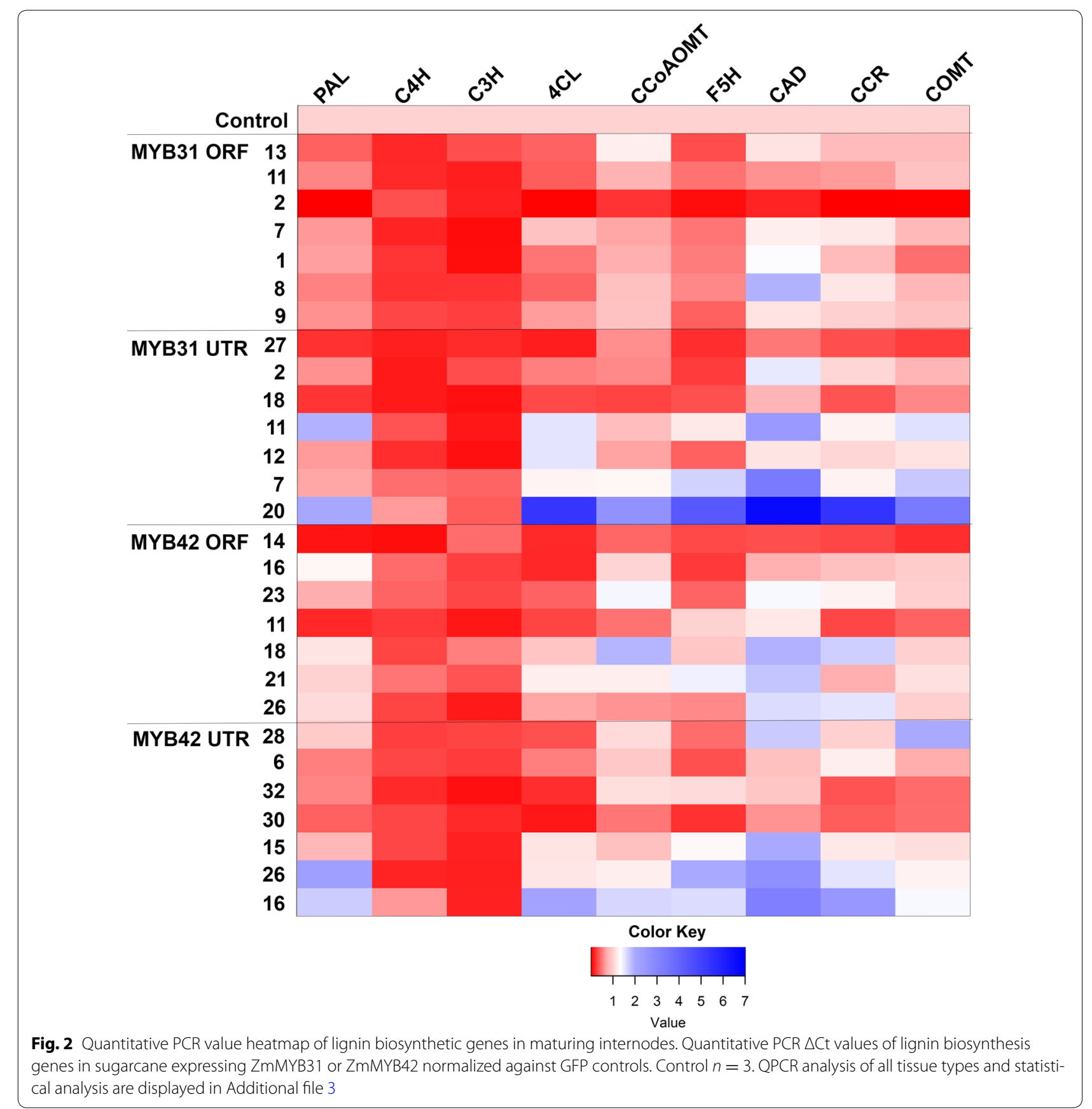

MYB42 (see Additional file 3). The lignin gene expression results for MYB31 aligned with the published results more closely than the MYB42 expression results.

\section{Cell wall compositional analysis of MYB transgenic sugarcane}

Cell wall compositional analysis was performed to determine acid-soluble and acid-insoluble lignin content, as well as cellulose (glucose) and hemicellulose (xylose, galactose and arabinose) content. Of the MYB31-expressing sugarcane lines, only MYB31UTR 27 showed a significant decrease in total lignin content (Fig. 3; Additional file 4). This same plant also had significantly decreased acid-soluble lignin while having significantly increased glucose and xylose (Fig. 4; Additional file 4). Two other MYB31UTR plants showed a significant decrease in acidinsoluble lignin and a significant increase in xylose (see Additional file 4). Approximately, half the MYB31 plants 

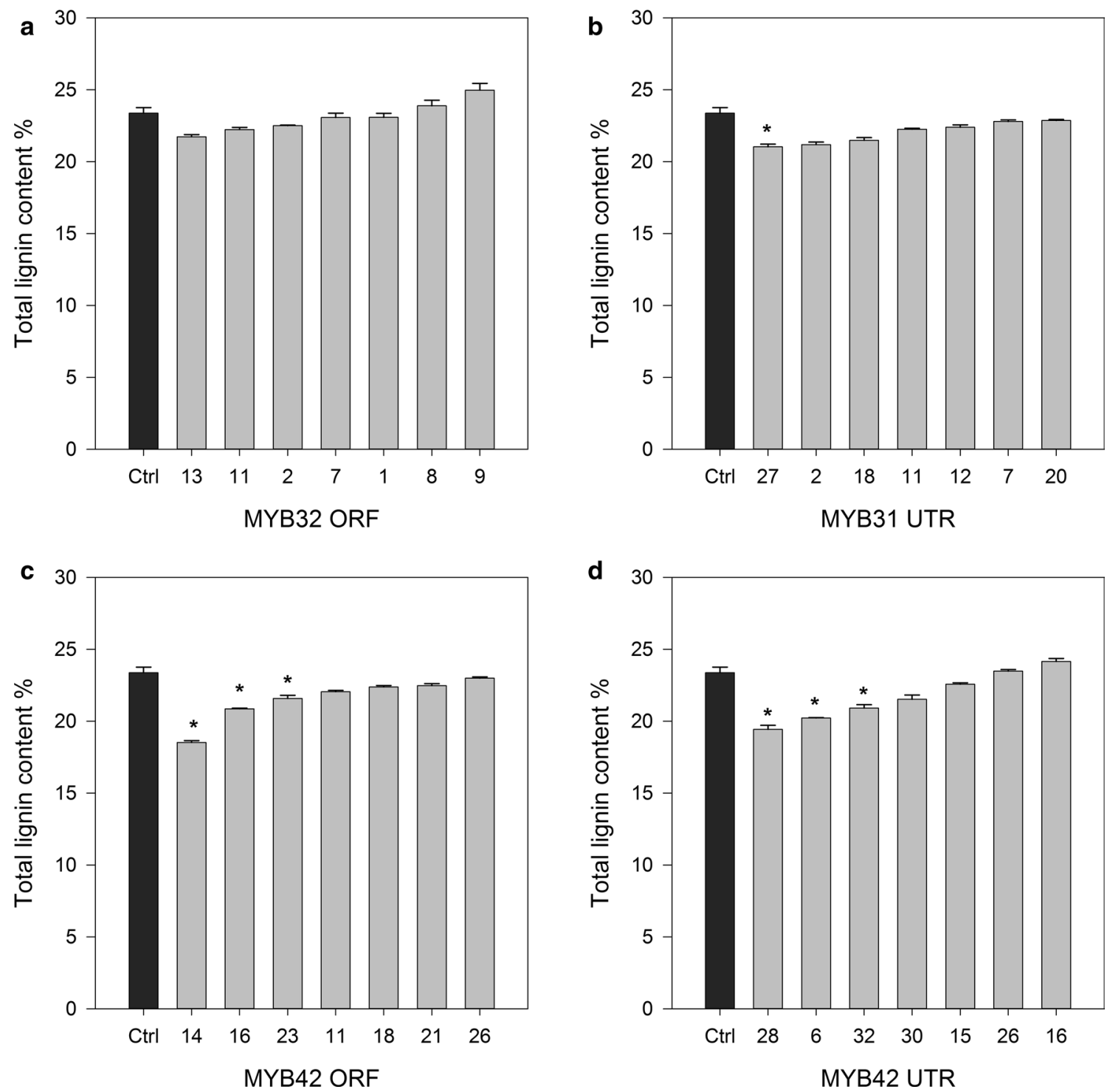

Fig. 3 Total lignin content (\%) of MYB32 and MYB42 transgenic sugarcane. Lignin content was quantified by a modified acid hydrolysis method. Acid-soluble lignin was determined by spectrophotometry and acid-insoluble lignin was measured gravimetrically. Acid-soluble lignin and acidinsoluble lignin were summed to determine total lignin content. a MYB31ORF, b MYB31UTR, c MYB42ORF and d MYB42UTR. Samples significantly different from the GFP controls after ANOVA followed by LSD test, $p=0.05$, are shown with asterisk. Control $n=3$. Data on all lines and statistical analysis are displayed in Additional file 4

(ORF and UTR) had significantly increased xylose and galactose (Fig. 4; see Additional file 4). Overall, MYB31 expression appeared to have little impact on lignin and glucose levels, but increased the synthesis of structural hemicelluloses. There were no changes in ash content in MYB31-expressing lines.

Six sugarcane plants expressing MYB42 (three ORF plants and three UTR plants) showed a significant decrease in lignin content (Fig. 3). This was the result of significant decreases in acid-insoluble lignin (see
Additional file 4) as there were no significant changes to the acid-soluble component. Of these six plants, two had significant increases in glucose content (Fig. 4; see Additional file 4). There were significant increases in xylose, galactose and arabinose contents, but these increases were not specific to lignin-reduced plants. Significant decreases in structural carbohydrate contents were not found in any MYB42 plants. Only one of the fully characterized MYB42 lines (42ORF 14) had a significant increase in ash content. Both $M Y B$ genes appeared to 

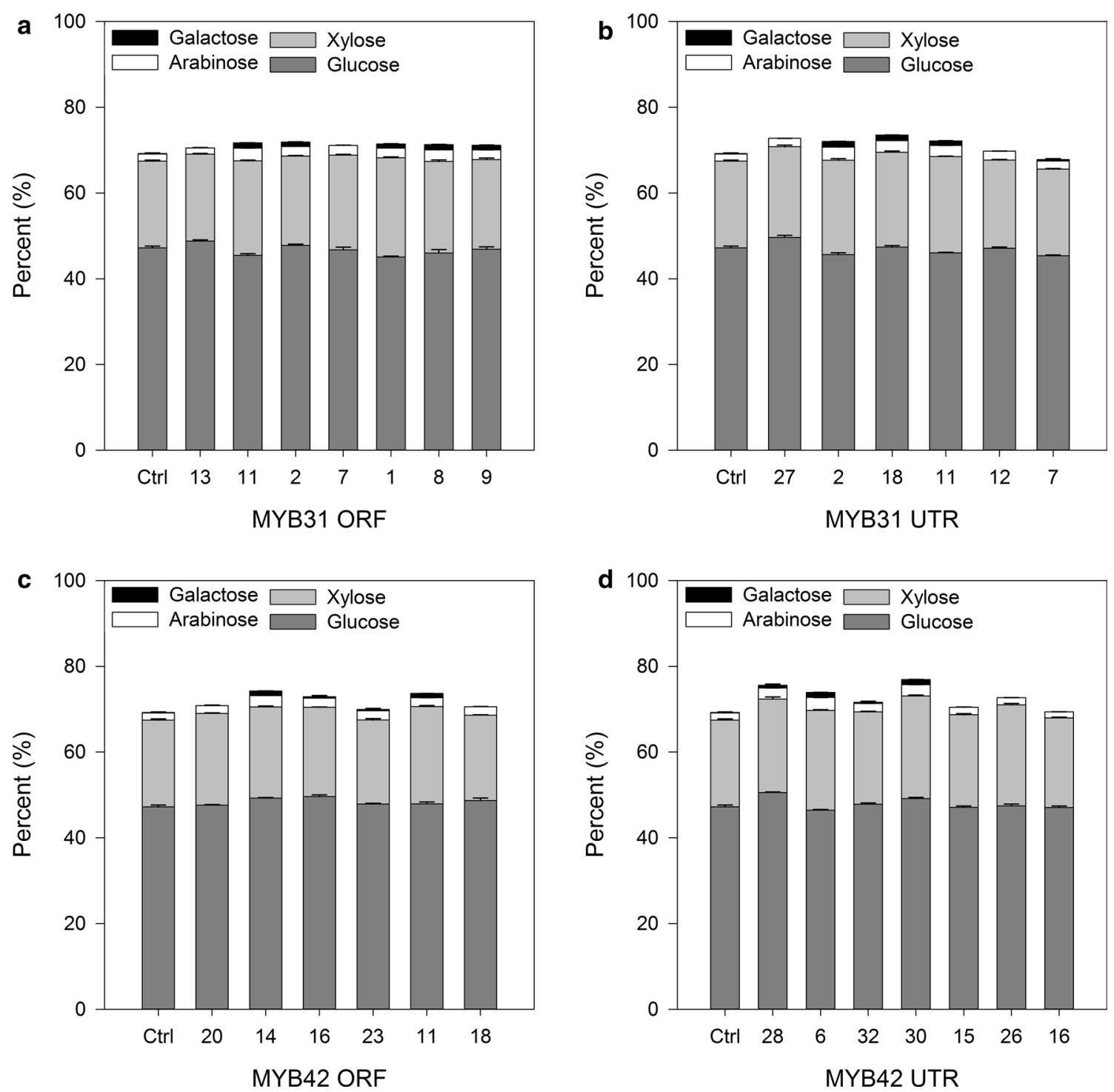

Fig. 4 Total carbohydrate content (\%) of MYB32 and MYB42 transgenic sugarcane. Cellulose and hemicelluloses were quantified by a modified acid hydrolysis method as described. a MYB31ORF, b MYB31UTR, c MYB42ORF and $\mathbf{d}$ MYB42UTR. The percentage of each component of the total composition is shown with the standard error of the mean. Data on all lines and statistical analysis are displayed in Additional file 4

have little effect on glucose content of plants, but the expression of MYB31 had a more consistent effect on hemicellulose components.

\section{Enzymatic hydrolysis of MYB and control bagasse samples}

The three MYB plants per line with the largest decrease in lignin composition were selected to undergo enzymatic hydrolysis (Fig. 5). Hydrolysis was carried out for $72 \mathrm{~h}$ with sampling at six time points. When compared with GFP controls, only two of the six MYB31-expressing plants showed a significant increase in glucose release after $72 \mathrm{~h}$, whereas all six MYB42-expressing plants released significantly more glucose than the GFP controls (Fig. 5; see Additional file 5).

Four MYB42 plants showed significantly higher rates of glucose conversion as early as the 6-h time point and continued to release significantly more glucose at each of the later time points (Fig. 5). The plants with significantly more glucose released after $72 \mathrm{~h}$ all showed signs of increased rate of glucose conversion by the 12-h time point (see Additional file 5). Significantly higher glucose released at earlier time points by the MYB sugarcane is indicative of an increased rate of cellulose conversion to glucose. 

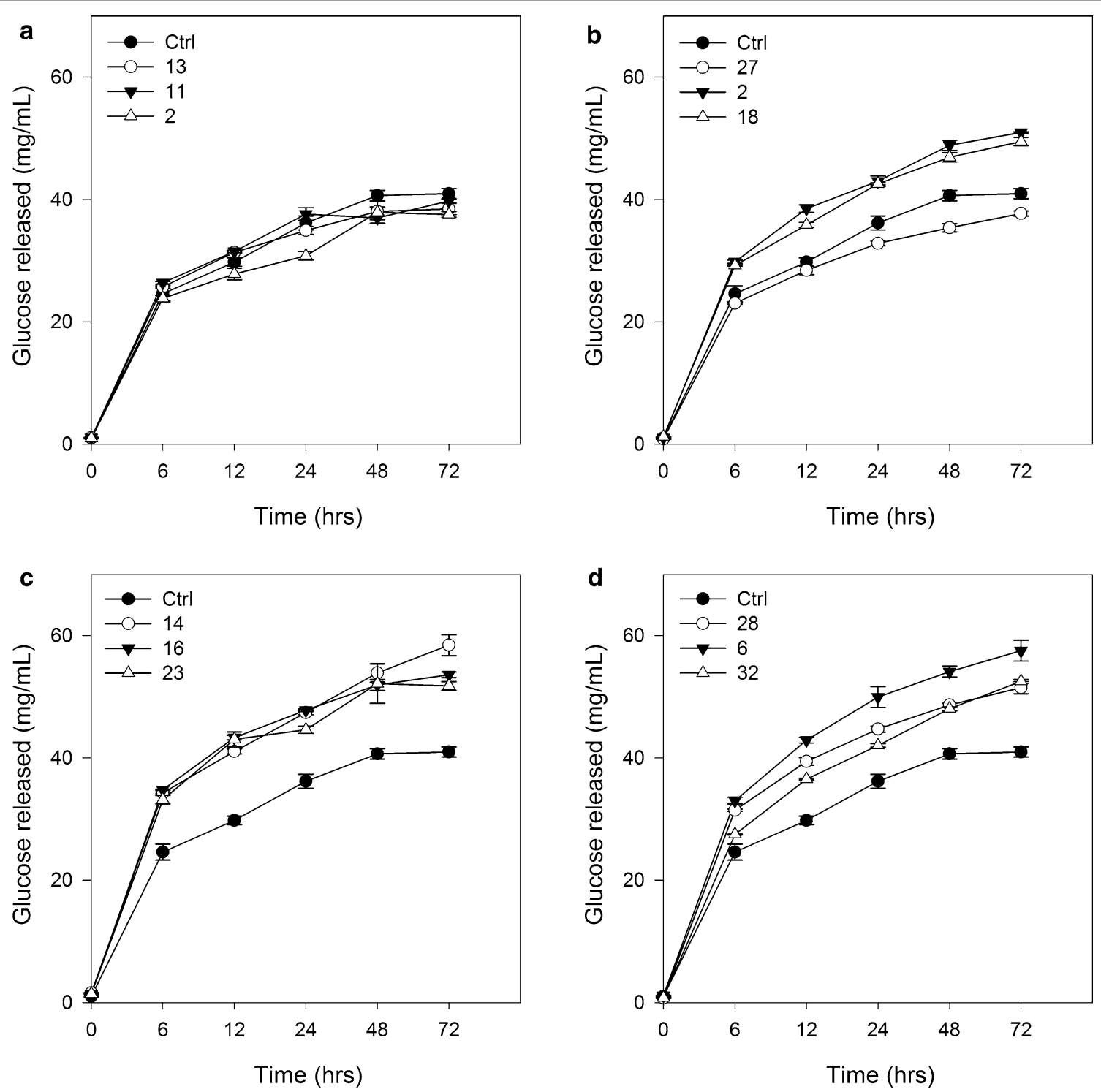

Fig. 5 Enzymatic hydrolysis of MYB32 and MYB42 transgenic sugarcane. Total glucose concentration in enzymatic hydrolysis solution ( $\mathrm{mg} / \mathrm{mL}$ ) per gram (g) of bagasse showing standard error of the mean measured at six time points over an incubation period of $72 \mathrm{~h}$ for $\mathbf{a}$ MYB31ORF plants, $\mathbf{b}$ MYB31UTR plants, c MYB42ORF, and d MYB42UTR using values from Additional file 5. Control $n=3$

\section{Cellulose crystallinity index and sucrose content of $M Y B$ bagasse}

The tissue requirements for pretreatment and enzymatic hydrolysis left enough bagasse for only two GFP control plants and five MYB plants to undergo determination of cellulose crystallinity index. Statistical analysis was not performed as the limited number of samples would not provide reliable results. The ranges of crystallinity were 49.03-51.49 \% for control plants and 45.56-47.50\% for MYB-expressing plants (see Additional file 6).

Plants that underwent enzymatic hydrolysis were also assessed for sucrose content of the extracted juice (Fig. 6) to determine if changes in lignin content or structure had affected juice composition and quantity. Overall, only MYB31 plants showed a significant decrease in sucrose content when compared against the GFP control plants (Fig. 6) and MYB42 plants were comparable to controls. Glucose and fructose were not detected in any of the samples. MYB31ORF 2 did not have sufficient tissue for juice analysis.

\section{Lignin composition and structure}

Samples with enough tissue remaining underwent NMR analysis to determine their lignin monomer compositions 

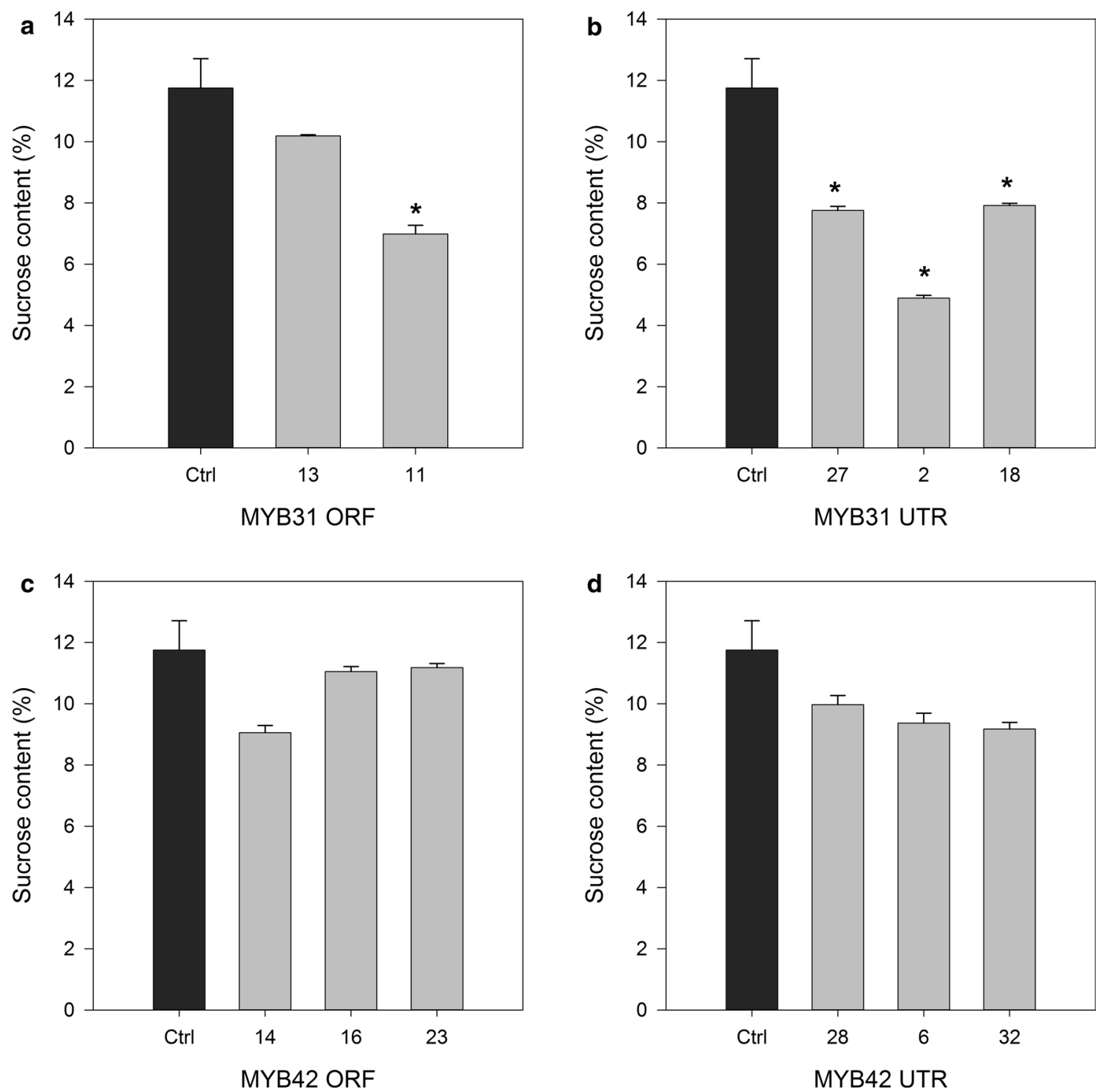

Fig. 6 Sucrose content of extracted juice of transgenic sugarcane plants. Sucrose content (\%/fresh weight) of extracted juice of transgenic sugarcane plants selected for enzymatic hydrolysis (showing standard error of the mean). a MYB31 ORF, b MYB31 UTR, c MYB42 ORF and d MYB42 UTR. An asterisk indicates a significant difference to GFP controls after ANOVA followed by LSD test, $p=0.05$. GFP $n=3$

and altered structural features (Fig. 7). GFP controls had an S:G of 70:30, whereas the MYB lines all had small reductions in S:G. Ferulate (that is essentially all from ferulate on arabinoxylan) levels were all low $(\sim 1-2 \%$ on an $\mathrm{S}+\mathrm{G}=100 \%$ basis) across all lines, but $p$-coumarate (that is from both its acylation of arabinoxylans and of lignin) varied significantly with the MYB42 lines having lower levels than the control and the MYB31 line higher; the integrals of these end groups (Fig. 7) significantly overestimate the actual levels on a lignin basis in HSQC experiments [17], but the relative levels are indicative of the change. Changes in the levels of the major side chain structures A, B, C and $\mathbf{C}^{\prime}$ (Fig. 7) are also evident. Particularly intriguing (see the Discussion) is the appearance of structures $\mathbf{C}^{\prime}$ in the MYB31 line, indicating that its lignin chain initiation is different from the other lines, including the GFP control.

\section{Discussion}

ZmMYB31 and ZmMYB42 belong to the R2R3-MYB superfamily of MYB transcription factors that are known to be involved in the regulation of the lignin biosynthetic pathway [12]. The R2R3 domains of MYB transcription factors bind to conserved $\mathrm{AC}$ elements within 

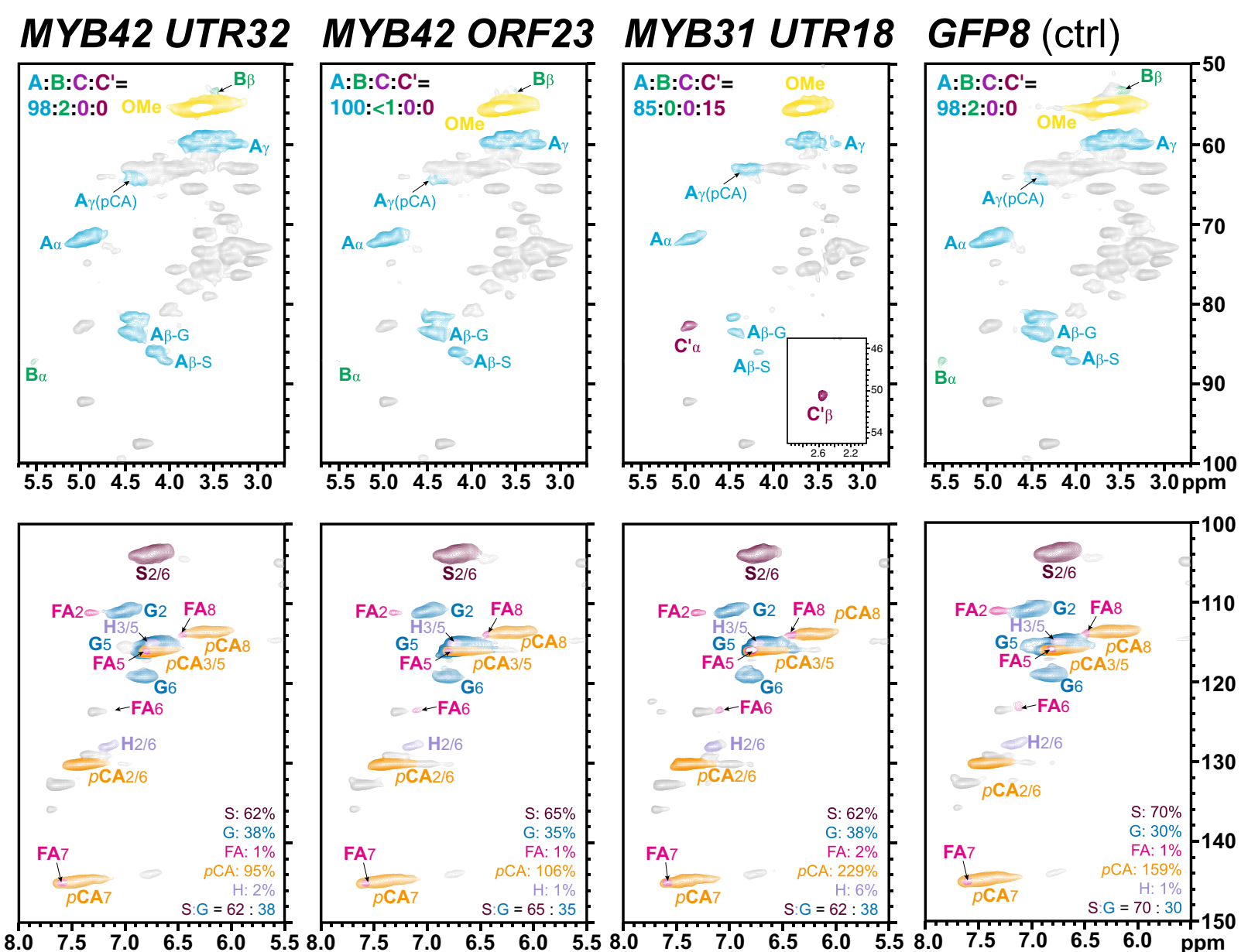

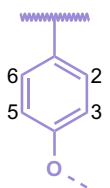

$\mathrm{H}$

p-Hydroxyphenyl<smiles>COc1ccc(C(C)(C)C)cc1OC</smiles>

G

Guaiacyl<smiles>COC(=O)C=Cc1ccc(OC)c(OC)c1</smiles>

FA Ferulate

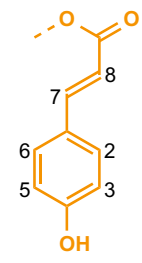

pCA p-Coumarate

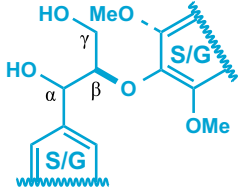

A

$\beta$-aryl ether $(\beta-O-4)$

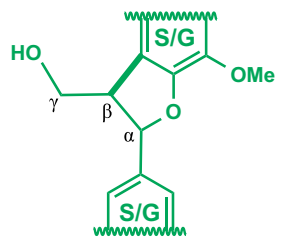

B

phenylcoumaran ( $\beta-5)$

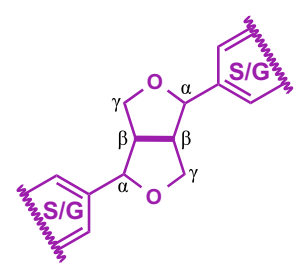

C

Fig. 7 Partial 2D HSQC NMR spectra. Enzymatic lignins from the two MYB42 and the one MYB31 transgenic sugarcane bagasse, along with the GFP control in DMSO- $d_{6} /$ pyridine- $d_{5}(4: 1)$. The top row shows the aliphatic region, with color-coded assignments of the main lignin to the same-colored corresponding structures. The bottom row shows the aromatic and double-bond region showing the lignin polymer $\mathrm{H}, \mathrm{G}$, and $\mathrm{S}$ structural units along with ferulates (mainly from feruloylated arabinoxylan polysaccharides) and p-coumarates (on both lignin and polysaccharides); again, contour coloration matches that of the structures shown. The aromatic unit quantification values are from volume integration, on an $S+G=100 \%$ basis; accuracy is generally good for the H:G:S units, but $p$-coumarate and ferulate end groups are severely overestimated, so their integrals should be used only for comparative purposes [17] 
the promoters of lignin biosynthetic genes, allowing for regulation of gene expression levels [11, 18-20]. The cloned sequences of $Z m M Y B 31$ and $Z m M Y B 42$ were 99 and $98 \%$ identical to the sequences published by Fornale et al. [12]. The R2R3 domains of the cloned sequences were $100 \%$ identical to the published sequences. The differences are attributed to the varietal differences in corn used for cloning purposes and did not appear to negatively affect the expression of the MYB genes (Fig. 1; see Additional file 1) or their overall ability to downregulate the expression of genes within the lignin biosynthetic pathway (Fig. 2; see Additional file 2). Inclusion of UTR sequences has been shown to improve gene expression [21-25]. Although the constructs containing UTR sequences for both MYB31 and MYB42 produced more PCR- and qPCR-positive plants than their ORF counterpart, retaining or omitting the UTR sequences did not appear to affect the level of downregulation of lignin biosynthetic genes, deposition of cell wall components, juice sucrose levels, or plant phenotype in plants expressing MYB31 or MYB42. All MYB42ORF and MYB42UTR plants analyzed released significantly more glucose, indicating that the UTR sequences did not contribute any additional benefits to the enzymatic hydrolysis of bagasse. This could be due to the non-native maize promoter and UTR used here in sugarcane and the UTR effect being species specific [26]. However, including the UTR sequences did result in an increase in MYB31expressing plants that released significantly more glucose after enzymatic hydrolysis.

$Z m M Y B 31$ and $Z m M Y B 42$ are known to downregulate multiple genes within the lignin biosynthetic pathway [10-12], and this downregulatory control was also observed in this study. MYB31 appears to downregulate all genes analyzed except $C A D$, whereas MYB42's regulatory effects are more subtle. Although approximately half of the genes analyzed appear to be downregulated by MYB42, half appear to be upregulated. The genes downregulated by MYB42 generally appear earlier in the lignin biosynthetic pathway, and the genes upregulated function later in the pathway. The downregulatory effects of MYB31 were more consistent across the three tissue types analyzed than MYB42. These results suggested that MYB31 would reduce lignin content in sugarcane bagasse to a greater extent than MYB42.

Previous research showed a strong correlation between reduction of lignin gene expression by $M Y B$ genes and reduction in lignin content $[10,11,14,27,28]$. Of the 14 MYB31-expressing sugarcane lines analyzed, only MYB31UTR 27 had a significant decrease in total lignin, by $10 \%$. Lines MYB31UTR 2 and MYB31UTR 18 had $13 \%$ reductions in acid-insoluble lignin but not total lignin. This is far from the eightfold [12] and $70 \%$ [11] decreases in lignin content previously reported in Arabidopsis after the transgenic expression of MYB31. This difference may simply be due to the use of different promoters and terminators. However, it is more likely due to the large and complex polyploid sugarcane genome [29] that increases the likelihood of the existence of gene homologs. It is possible that MYB31 was only able to downregulate a number of these potential homologs in the current study, with the decreased expression compensated by unregulated homologs, thus reducing the overall regulatory effect of MYB31 on lignin biosynthesis. In addition, copy number was not assessed in these lines and can play a role in effect variability [30].

As is increasingly realized, pathways in general and the lignin biosynthetic pathway in particular differ significantly between monocots and dicots [31]. The side chain region of the spectra (Fig. 7, top row) showed some intriguing features. First is a feature even stranger than that recently commented on in maize [32]. The GFP control, but also the MYB42 lines, that were all S-G lignins with similar S:G, had abundant $\beta$-ether units $\mathbf{A}$ and small amounts of phenylcoumarans $\mathbf{B}$; as noted in maize, there were imperceptible levels of the resinol units $\mathbf{C}$ that in dicots with similar S:G are at significant levels (5-10\%), derive from sinapyl alcohol dimerization, and represent the stating points of lignin polymerization. These sugarcane lines, therefore, appear to have lignin chains that are not initiated by monolignol dimerization. As these samples have little-to-no tricin, a flavone that was recently discovered in most monocots that nucleates lignin chain formation [31-33], the only discernible way that chains can initiate is from the ferulates (and diferulates) on arabinoxylans, as reviewed recently [34]. Even more intriguingly, the MYB31 line, with only slightly lower S:G than the control, exhibits the very clear presence, not of resinol units $\mathbf{C}$, but of analogous units $\mathbf{C}^{\prime}$ that derive from dimerization of acylated monolignols, primarily sinapyl $p$-coumarate, as in wild-type maize [34]. Clearly, these units are chain initiators in this MYB31 line, but not (to any significant degree) in the other lines. In another report on sugarcane bagasse NMR spectra, the whole cell walls appeared similarly devoid of $\beta-\beta$-coupling products $\left(\mathbf{C}\right.$ and $\left.\mathbf{C}^{\prime}\right)$, but both were revealed at low levels in the spectra of isolated Björkman lignins [35]. Our enzyme lignins here represent essentially all of the lignin in the sample, but have a higher level of residual polysaccharides than purified Björkman lignins. We offer no explanations for the intriguing observations noted here between the lignins in sugarcane vs maize, but simply stress that these add to the contention that lignification in monocots is significantly different from that in dicots and that mysteries regarding the process and the structural features of the polymer remain. 
Approximately, half of the MYB31-expressing sugarcane plants (ORF and UTR) had significantly increased xylose and galactose, whereas Fornale et al. [11] reported no changes in the structural carbohydrate composition of lignin-reduced Arabidopsis. Within sugarcane, $Z m M Y B 31$ expression appears to have little impact on lignin and glucose levels, but increases the synthesis of hemicelluloses.

Six sugarcane plants expressing MYB42 (three ORF plants and three UTR plants) showed a significant decrease in total lignin content of 8-21 \% (Fig. 3), whereas previous research found the Arabidopsis plants expressing MYB42 had greater reductions in lignin content, of 2.1-fold [12] and $60 \%$ [10] in different studies. Two sugarcane events had significant increases in glucose content, whereas no changes in cellulose content were found in MYB42-expressing Arabidopsis [10]. Hemicelluloses were increased in Arabidopsis [10] as well as in several MYB42-expressing sugarcane plants. These changes in carbohydrate content did not correlate with changes in lignin content.

These results suggest that, within sugarcane, MYB42 affects the deposition rates of lignin, whereas MYB31 increases the hemicellulose content within secondary cell walls, but may have little effect on lignin production. The finding that MYB31 downregulated the expression levels of the lignin biosynthetic pathway genes to a greater extent than MYB42, but lignin deposition was more influenced by MYB42 than MYB31, suggests that gene transcription levels may not necessarily reflect translation levels of lignin biosynthetic genes. It is possible that the genes with higher expression levels in young internode tissue have gene products that may persist during tissue maturation, allowing for continued lignin biosynthesis without the need for continued high expression of these genes. Although the genes of the lignin biosynthetic pathway have been well characterized, a full understanding of metabolic flux through the pathway remains to be established, making it difficult to predict the outcomes of modifying gene expression levels. Assaying the enzymatic activity of translated lignin biosynthetic genes, or the concentration of enzyme product throughout the stem, would provide a clearer picture of the regulatory effects of $Z m M Y B 31$ and ZmMYB42 expression over these genes.

Reduced lignin content in sugarcane has previously led to improved saccharification [13, 36-39] as has the expression of MYB31 and MYB42 in Arabidopsis [10, 11]. The expression of $P v \mathrm{MYB} 4$ in transgenic switchgrass is the only report of a monocot species having improved saccharification resulting from the expression of an $M Y B$ gene $[14,15]$. This is the first report of the expression of MYB31 and MYB42 in a monocot, and the first report of
$M Y B$ transcription factors being expressed in sugarcane to alter lignin biosynthesis for improved biofuel production. In this study, the three plants with the least amount of total lignin from each line were assessed for enzymatic hydrolysis performance against controls over a period of $72 \mathrm{~h}$. At $72 \mathrm{~h}$, the MYB42 lines performed better than the MYB31 lines and GFP controls. These plants also had a faster rate of glucose conversion than controls. The compositional analysis showed that all six of these plants had significant reductions in total lignin as a result of reductions in acid-insoluble lignin. In contrast to these results, no MYB31ORF plants and only two MYB31UTR plants had higher levels of glucose released than controls at $72 \mathrm{~h}$. The MYB31ORF results are unsurprising, as no MYB31ORF plants had reductions in lignin (see Additional file 4). However, MYB31UTR 27 had significantly less total lignin, but did not release significantly more glucose, whereas MYB31UTR 2 and MYB31UTR 18 did not have significantly less total lignin, but did release significantly more glucose; the latter observation is likely due to the significant reductions in acid-insoluble lignin in these two plants, or maybe due to changes in lignin composition and structure, as MYB31UTR 18 was shown to have a similar S:G ratio to the other MYB lines (and slightly lower than the control) and a lot higher level of $p$-coumarate (although it is not clear whether this is on the lignin or the hemicelluloses) relative to GFP controls (Fig. 7). The finding that all MYB31 and MYB42 plants with significant reductions in acid-insoluble lignin content performed significantly better than transgenic controls after enzymatic hydrolysis suggests that this cell wall component is a primary influencing factor on enzymatic hydrolysis performance. Decreases in acid-insoluble lignin have also been reported alongside improvements in saccharification in switchgrass [40], maize [41] and Arabidopsis [10, 11].

The current finding that MYB42 lines outperformed MYB31 lines during enzymatic hydrolysis is supported by previous research. In transgenic Arabidopsis, the expression of MYB42 improved the enzymatic hydrolysis by $68 \%$ [10] compared with an increase of $14 \%$ after the expression of MYB31 [11]. Due to limited bagasse available for analysis, the enzymatic hydrolysis section of this study utilized one pretreatment condition $(1 \% \mathrm{w} / \mathrm{w}$ sulfuric acid) and subsequently a single digestive enzyme cocktail mix at one concentration (six FPU Accellerase 1500 with the addition of $\beta$-glucosidase). Of the different pretreatments available, mild acid pretreatment was selected, as this would not change the lignin content of bagasse and disrupts the hemicellulose content of lignocellulosic biomass to expose the cellulose to hydrolytic enzymes [42, 43], thus better elucidating any digestive differences between bagasse samples with differences 
in lignin content. A low FPU concentration was used to again better elucidate any differences in bagasse digestibility. It would be expected that the use of different pretreatment conditions or cocktail mixes or concentrations would produce different results. For example, if an alkaline pretreatment was used, which removes lignin as opposed to hemicellulose [43], it would be expected that transgenics and wild types would release similar amounts of glucose as the glucose contents between controls and transgenics do not overly differ.

For transgenic sugarcane expressing MYB genes to be beneficial to, and accepted by, the sugarcane industry, it is important that any change in cell wall composition is not detrimental to the phenotype of the sugarcane or to the juice sucrose levels that are the cornerstone of the sugarcane industry. The sucrose content did not significantly decrease in MYB42 plants tested, even though these same plants had significantly reduced lignin content. These MYB42 plants also showed increased glucose release from the bagasse. It therefore appears to be possible to produce sucrose and improved biomass in a single plant. Overall, the majority of phenotypic differences were in internode diameter and length for both MYB31 and MYB42 plants, with few differences seen in plant height or total number of internodes. The differences in phenotypic measurements were not specific to plants with significantly reduced lignin contents or altered polysaccharide contents. Previous research has reported decreased growth rates and dwarfed phenotypes after MYB directed lignin reductions in poplar and Arabidopsis [44], tobacco [14, 27, 45] and switchgrass $[14,15]$. Reduced height was also observed in Arabidopsis expressing ZmMYB31 and ZmMYB42 [10-12]. The absence of a strong detrimental phenotype in the current study may be due to the relatively low levels of $M Y B$ transgene expression. It is possible that alterations in lignin biosynthesis can also have an impact on a plants' resistance to pests and pathogens [46]. This was not assessed in the MYB-overexpressing sugarcane, but would be a necessary assessment prior to commercial use.

Arabidopsis expressing MYB31 [11] and MYB42 [10] with reduced height had severe lignin reductions of up to 70 and $60 \%$, respectively. Vanholme et al. [47] suggested that more modest lignin reductions may not result in these detrimental phenotypes, as is supported by the current findings. Of the six MYB31 plants that underwent enzymatic hydrolysis, only one plant had a decrease in total lignin and two plants in acid-insoluble lignin of 10 and $13 \%$ (see Additional file 4). This is better highlighted by the MYB42 plants in this study. The six MYB42 plants that underwent enzymatic hydrolysis had significant reductions in lignin content (Fig. 3; see Additional file 5), but were not different in height to controls (Table 1). The greatest lignin reduction was by $21 \%$ in MYB42ORF 14 , which is modest when compared with the $60-70 \%$ reductions previously reported in detrimental phenotypes $[10$, 11] and may help explain why the MYB31 and MYB42 lignin-reduced plants in this research did not show any height differences. Some of these lignin-reduced plants did show differences in average internode diameter and length that may be attributed to the changes in cell wall production.

\section{Conclusions}

Although MYB31 expression resulted in the downregulation of many genes within the lignin biosynthetic pathway, this did not carry over to cell wall synthesis, as only a limited number of MYB31 sugarcane plants had reductions in lignin content. This limited the potential saccharification improvements of MYB31 expression. Alternatively, MYB42 expression in sugarcane more closely met the aims of this research, with all MYB42 plants analyzed by enzymatic hydrolysis having increased glucose release with no reduction to juice sucrose levels and minimal phenotypic effects. This research highlights $Z m M Y B 42$ as a transcription factor of interest for improving the production of second-generation bioethanol from sugarcane bagasse.

\section{Methods}

\section{Cloning of $Z m M Y B 31$ and $Z m M Y B 42$}

RNA was extracted from combined maize leaf and stem tissues sourced from locally grown sweet corn and used for cDNA synthesis. Primers were designed from available sequence information to amplify MYB31 and MYB42 genes from maize cDNA (see Additional file 7). Two amplicons were cloned for each $M Y B$ gene to either include or exclude the adjacent sequence of the $5^{\prime}$ and $3^{\prime}$ untranslated regions (UTR) (see Additional file 1), as there is evidence that inclusion of UTR sequences may improve the expression [22]. 'MYB UTR' refers to DNA with the inclusion of untranslated regions and 'MYB ORF' refers to the open reading frame only. MYB31UTR and MYB42UTR had 128 and $64 \mathrm{bp}$ of $5^{\prime}$ UTR and 251 and 32 bp of $3^{\prime}$ UTR, respectively, amplified. The resulting PCR products were cloned into the pGEM-T Easy Vector System. After sequence confirmation, fragments were subcloned into the SmaI site of an existing alkaline phosphatase-treated $Z m U$ Ubi-iUbi-nos/pBlueScript entry vector containing the maize Ubiquitin promoter (Ubi) and intron (iUbi) $[48,49]$ and the nopaline synthase (nos) terminator [50], resulting in four ZmUbi-iUbi-MYB-nos/ pBS constructs. 
Sugarcane transformation and regeneration of plants Callus was co-bombarded with individual $Z m U b i-i U b i-$ $M Y B-n o s / p B S$ constructs and ZmUbi-iUbi-nptII-nos/ pUC19. Transformation control callus was co-bombarded with $1 \mu \mathrm{g}$ ZmUbi-iUbi-GFP-nos/pUC19 constructs with $1 \mu \mathrm{gg}$ of $Z m U$ Ubi-iUbi-nptII-nos/pUC19. Regeneration of callus was carried out as previously described [51], after which individual events were transferred to growth chambers for continued development. The confirmed $Z m U$ Ubi-iUbi-GFP-nos plants served as transgenic controls.

Tissue culture plantlets selected for acclimatization were transferred to growth rooms under a $16 \mathrm{~h}$ photoperiod at $25{ }^{\circ} \mathrm{C}$ with watering every second day. When the plants reached approximately $30 \mathrm{~cm}$ in height, they were transferred to the greenhouse and grown in $4.5 \mathrm{~L}$ pots at $27 \pm 3{ }^{\circ} \mathrm{C}$ under natural light. Plants were watered to saturation twice per week and fertilized with Aquasol (Yates) once per month with regular removal of tillers. Potted plants underwent periodic randomized position rotation within the glasshouse to minimize positional effects.

\section{Nucleic acid extraction and quantitative PCR}

DNA was extracted from 2- to 4-week-old leaf tissue using the rapid release method [48] with the addition of a chloroform:isoamyl alcohol (24:1) wash step after the $95{ }^{\circ} \mathrm{C}$ incubation [49]. A 1:4 dilution of the supernatant was used for subsequent PCR reactions. RNA was extracted from all tissue samples using Tri Reagent (Sigma, NSW, Australia) following the manufacturer's protocol using tissue ground under liquid nitrogen. Briefly, tissue was incubated at room temperature with Tri Reagent for $5 \mathrm{~min}$ before the addition of $200 \mu \mathrm{L}$ chloroform. Tubes were vigorously mixed and incubated at room temperature for a further $5 \mathrm{~min}$. The tubes were centrifuged $\left(12,000 \mathrm{~g}, 15 \mathrm{~min}, 4{ }^{\circ} \mathrm{C}\right)$ and the supernatant collected and mixed with an equal volume of isopropanol. After $10 \mathrm{~min}$ incubation at room temperature, the reactants were again centrifuged $\left(12,000 \mathrm{~g}, 10 \mathrm{~min}, 4{ }^{\circ} \mathrm{C}\right)$ and the RNA pellet subsequently washed in $75 \%$ ethanol before a final centrifugation $\left(7500 \mathrm{~g}, 5 \mathrm{~min}, 4{ }^{\circ} \mathrm{C}\right)$. The supernatant was removed and the pellet dried for $10 \mathrm{~min}$ before being resuspended in $30 \mu \mathrm{L}$ water and incubated at $60{ }^{\circ} \mathrm{C}$ for $10 \mathrm{~min}$. The extracts were kept on ice and used for cDNA synthesis immediately or stored at $-80{ }^{\circ} \mathrm{C}$. Extracted RNA $(1 \mu \mathrm{g})$ was digested with RQ1 RNase-free DNase (Promega, NSW, AUS) following the manufacturer's methods with the $37^{\circ} \mathrm{C}$ incubation being increased to $1 \mathrm{~h}$. After digestion, the samples were either used immediately for cDNA synthesis or stored at $-80{ }^{\circ} \mathrm{C}$. Complementary DNA synthesized from leaf tissue was used to confirm the presence of the transgene by qPCR analysis
$[27,52]$ with the addition of a chloroform:isoamyl alcohol (24:1) wash step after the $95{ }^{\circ} \mathrm{C}$ incubation [53]. A 1:4 dilution of the supernatant was used for subsequent PCR reactions. Plants confirmed to contain the $M Y B$ transgene cassette were sampled for RNA extraction, cDNA synthesis and qPCR quantification of $Z m M Y B 31$ or $Z m M Y B 42$ transcript level, as well as the expression of nine lignin biosynthesis pathway genes in the young and maturing internodes. Initially, cDNA was extracted from internode 1 (young tissue) and internode 7 (maturing tissue) for quantitative PCR (qPCR) analysis. Seven individual plants per MYB construct (28 MYB plants in total) were selected for this analysis based on these plants having the greatest number of lignin biosynthetic genes downregulated along with three GFP transgenic controls. See Additional files 7 and 8 for primers used for both end point and qPCR. Quantitative PCR was performed on all seven plants generated, but only three plants were selected for subsequent analysis.

\section{Harvest and line selection for analysis}

Events harboring the $M Y B$ gene and having detectable levels of $M Y B$ gene expression were transferred to the glasshouse and grown for 9 months before being destructively harvested for analysis. All plants were watered to saturation 2 days before harvesting to avoid results being affected by any potential drought-related stress response. The plants were harvested between $10 \mathrm{am}$ and $2 \mathrm{pm}$ in a single session to minimize light- or circadianrelated fluctuations in gene expression levels $[54,55]$ and occurred over four consecutive days. Before measuring and cutting, all leaf tissue and sheaths were removed, and the internodes were counted as per van Dillewijn [56]. The length of the stalk was measured (internode 1 to the final internode), the number of internodes was counted and the diameter of the third internode from the base was recorded using calipers. Analyses were performed in a predetermined order and used only harvested internode tissue.

Plants that were analyzed by qPCR in the internode tissues also underwent acid hydrolysis to quantify their cell wall composition. Enzymatic hydrolysis was performed on three plants per MYB line, selected based on having the lowest lignin contents after compositional analysis, and three GFP transgenic control plants over $72 \mathrm{~h}$ with sampling at six different time points. Quantification of juice sugar components was performed on the plants selected for enzymatic hydrolysis, where there was enough tissue remaining.

\section{Cell wall compositional analysis}

After harvest, tissue for cell wall compositional analysis was prepared as per [57] using convection oven drying at 
$40{ }^{\circ} \mathrm{C}$. Dried samples were milled with an IKA Labortechnik MFC mill (2 mm screen) and subjected to successive overnight Soxhlet washes with water and then ethanol to remove extractives [58]. Samples were again dried using convection oven drying at $40{ }^{\circ} \mathrm{C}$ and stored at room temperature. A sample of this prepared material was dried overnight in a convection oven set at $105^{\circ} \mathrm{C}$ and used to determine the total solids of the bagasse [59].

Lignin, cellulose and hemicelluloses were quantified by a modified acid hydrolysis method [58] using $0.125 \mathrm{~g}$ of bagasse and $1.5 \mathrm{~mL} 72 \%(\mathrm{w} / \mathrm{w})$ sulfuric acid. Acidsoluble lignin was determined by spectrophotometry, and acid-insoluble lignin and ash content was measured gravimetrically [58]. Structural carbohydrates were analyzed using high-performance liquid chromatography (HPLC) [58]. A Waters e2695 Separations Module and Shodex SP-0810 sugar column $\left(85^{\circ} \mathrm{C}\right)$ with micro-guard de-ashing columns (BioRad) equipped with a Waters 2414 Refractive Index Detector was employed. Samples for HPLC analysis were neutralized by addition of $\mathrm{CaCO}_{3}$ $(50 \mathrm{mg} / \mathrm{mL})$.

\section{Pretreatment of bagasse for enzymatic hydrolysis}

Finely ground bagasse (McCrone micronizing) was subjected to a mild pretreatment. This involved $1 \%(\mathrm{w} / \mathrm{w})$ sulfuric acid being added in a ratio of 10:1 with bagasse followed by autoclaving $\left(130{ }^{\circ} \mathrm{C}\right.$ for $\left.30 \mathrm{~min}\right)$. Samples were then washed with water. Total solid content (\%) [59] was determined before use for enzymatic hydrolysis. Non-pretreated bagasse samples were used as a control during enzymatic hydrolysis to confirm the effectiveness of pretreatment. Samples then underwent acid hydrolysis as described above [58] to quantify lignin, cellulose and hemicellulose contents of the pretreated samples.

\section{Enzymatic hydrolysis of bagasse}

Enzymatic hydrolysis of transgenic and GFP control bagasse was performed using Accellerase 1500 (Genencor). Before use, the filter paper units (FPU) and protein concentrations of the enzyme solution were determined. The FPU activity of Accellerase 1500 was calculated with the methods by [60], using $50 \mathrm{mM}$ citrate buffer, and was determined to be $46.8 \mathrm{FPU} / \mathrm{mL}$. The protein content of Accellerase 1500 was determined using a Bradford assay [61] and was found to be $22.87 \mathrm{mg} / \mathrm{mL}$. Bovine serum albumin was used to develop a protein standard curve.

Enzymatic hydrolysis was performed following published methods [62]. Ground bagasse samples were mixed with $50 \mathrm{mM}$ sodium acetate $+0.02 \%(\mathrm{w} / \mathrm{v})$ sodium azide to a concentration of $1.3 \%$ cellulose (w/v) and rotated overnight by a Suspension Mixer (Ratek) at $4{ }^{\circ} \mathrm{C}$. A $2 \times$ enzyme master mix was prepared containing Accellerase 1500 and Aspergillus niger $\beta$-glucosidase
(Megazyme) to ensure complete hydrolysis of cellobiose to glucose. The final reaction concentration of Accellerase 1500 was $6 \mathrm{FPU}(2.93 \mu \mathrm{g} / \mathrm{g}$ cellulose $)$ and $\beta$-glucosidase was $50 \mu \mathrm{g} / \mathrm{g}$ cellulose. A $100 \mu \mathrm{L}$ aliquot of the bagasse suspension was mixed with $100 \mu \mathrm{L}$ of the $2 \times$ enzyme master mix resulting in a final cellulose concentration of $0.65 \%(\mathrm{w} / \mathrm{v})$.

Both pretreated and non-treated control bagasse samples were digested in triplicate at $50{ }^{\circ} \mathrm{C}$ with rotation for $72 \mathrm{~h}$ with samples being taken at $0,6,12,24,48$ and $72 \mathrm{~h}$. Reactions were quenched in liquid nitrogen and stored at $-80{ }^{\circ} \mathrm{C}$. The glucose released in each sample was analyzed using a D-Glucose Assay (GOPOD Format) (Megazyme) following the manufacturer's instructions.

\section{Determination of cellulose crystallinity index in bagasse}

Finely ground bagasse was used to determine the cellulose crystallinity index following the methods of Segal et al. [63]. X-ray diffraction patterns of cellulose samples were recorded with a Bruker AXS D8 Advance X-ray diffractometer at room temperature from 10 to $40{ }^{\circ} \mathrm{C}$ using $\mathrm{Cu} / \mathrm{K \alpha}_{1}$ irradiation (1.54 $\AA$ ) at $40 \mathrm{kV}$ and $40 \mathrm{~mA}$. The scan speed was $15 \mathrm{~s} / \mathrm{step}$ with a step size of 0.05 . The crystallinity Index (CI) was obtained from the relationship between the intensity of the 002 peak for cellulose $\mathrm{I}\left(\mathrm{I}_{002}\right)$ and the minimum dip $\left(\mathrm{I}_{\mathrm{am}}\right)$ between the 002 and the 101 peaks using the equation: $\mathrm{CI}(\%)=\left(\left(\mathrm{I}_{002}{ }^{-}\right.\right.$ $\left.\left.\mathrm{I}_{\mathrm{am}}\right) / \mathrm{I}_{002}\right) \times 100$, where $\mathrm{I}_{002}=$ intensity at $22.7 \AA$ and $I_{\mathrm{am}}=18 \AA$. The divergence slit and anti-scatter slit were $3.722^{\circ}$. The program XRD commander (Bruker) was used to collect and analyze the data from the diffractometer.

\section{Juice extraction and component quantification}

Juice was hot water extracted from internodes ground under liquid nitrogen following the methods of InmanBamber et al. [64]. Juice samples were diluted according to ICUMSA method GS7/8/4-24 using lactose as an internal standard and quantified using high-performance ion chromatography (HPIC). A Waters e2695 Separations Module and Dionex CarboPac PA1 HPLC column with guard column $\left(27^{\circ} \mathrm{C}\right)$ (Thermo-Fisher Scientific) equipped with a Waters 2465 Electrochemical detector was employed.

\section{Preparation of samples for NMR analysis}

The whole plant cell wall gel-state NMR samples were prepared as previously described [65]. In brief, the dried cell wall sample was pre-ground for $30 \mathrm{~s}$ in a Retsch MM400 mixer mill at $30 \mathrm{~Hz}$, using zirconium dioxide $\left(\mathrm{ZrO}_{2}\right)$ vessels $(10 \mathrm{~mL})$ containing $\mathrm{ZrO}_{2}$ ball bearings $(2 \times 10 \mathrm{~mm})$. The cell walls were extracted with distilled water (ultrasonication, $1 \mathrm{~h}$, three times) and $80 \%$ ethanol (ultrasonication, $1 \mathrm{~h}$, three times). The cell walls were 
dried and finely milled using a Fritsch planetary micro mill PULVERISETTE 7 (Germany) at $600 \mathrm{rpm}$ with zirconium dioxide vessels $(20 \mathrm{~mL})$ containing with zirconium dioxide ball bearings $(10 \mathrm{~mm} \times 10)$. Each sample (200 mg) was ground for a total of $2 \mathrm{~h} 40 \mathrm{~min}$ (interval: $10 \mathrm{~min}$, break: $5 \mathrm{~min}$, repeated $11 \times$ ). The cell walls were suspended in sodium acetate buffer ( $45 \mathrm{~mL}, \mathrm{pH} 5.0$ ), inoculated with Cellulysin ${ }^{\mathrm{TM}}$ (100 mg, Calbiochem, USA) and incubated at $35{ }^{\circ} \mathrm{C}$ for $72 \mathrm{~h}$. The solids were pelleted by centrifugation ( $20 \mathrm{~min}, 8000 \mathrm{rpm}$ ). The pelleted material was collected and treated with Cellulysin a second time. After the second cellulose treatment the pelleted material was washed three times with $\mathrm{RO}$ water $(45 \mathrm{~mL}$, ultrasonication $10 \mathrm{~min}$, pelleted by centrifugation). After lyophilization, the obtained enzymatic lignin $(30 \mathrm{mg})$ was

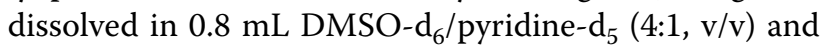
subjected to NMR characterization.

\section{NMR analysis of lignin monomer composition and structure}

NMR spectra were recorded at $25^{\circ} \mathrm{C}$ on a Bruker Biospin (Billerica, MA) AVANCE $700 \mathrm{MHz}$ spectrometer fitted with a cryogenically cooled $5 \mathrm{~mm}$ QCI gradient probe with inverse geometry (proton coil closest to the sample). Bruker's Topspin 3.1 (Mac) software was used to process the spectra. The central solvent peak was used as the internal reference $\left(\delta_{\mathrm{C}} / \delta_{\mathrm{H}}:\right.$ DMSO- $\left.\mathrm{d}_{6}, 39.5 / 2.95\right)$ HSQC NMR experiments for the whole plant cell wall gel-state samples were performed as previously described [17, 65-67].

\section{Statistical analysis}

Statistical analysis involved either a two-tailed $t$ test assuming unequal variance, $p=0.05$, or a one-way ANOVA with Tukey post hoc analysis or LSD to determine letter groupings, $p=0.05$, as appropriate, comparing transgenic plants to transgenic controls. As phenotypic measurements could only be made once per transgenic plant, the number of standard deviations $(z$ scores) for each MYB plant measurement were calculated against the GFP transgenic controls. Measurements were considered different to controls if a $z$ score was greater than 2 or -2 .

\section{Additional files}

Additional file 1: Figure S1. Nucleotide and amino acid alignments of MYB31 and MYB42. Alignments of published (Fornalé et al. 2006) and cloned nucleotide and amino acid sequences (ORF and UTR) for ZmMYB31 (NM_001112479) and ZmMYB42 (NM_001112539). Alignments were made using the Kyoto University Bioinformatics Center website (http://www.genome.jp/tools-bin/clustalw) and amino acid translations were made using the ORF region of each MYB nucleotide sequences and Vector NTI software. The start and stop codons are underlined in nucleotide sequence alignments with the $5^{\prime}$ and $3^{\prime}$ UTR regions being upstream and downstream of the start and stop codons respectively. The R2 and R3 motifs in each sequence are underlined with light gray and dark grey shading respectively.

Additional file 2: Table S1. Normalized MYB genes $\triangle C$ t values. Mean $\triangle C$ t value for MYB31 and MYB42 genes. Values represent post-harvest expression results from young internode tissue and maturing internode tissue. SE: standard error of the mean. Control $n=3$. Letter groupings were determined by ANOVA followed by LSD test.

Additional file 3: Table S2. Normalized lignin biosynthetic genes $\Delta \mathrm{Ct}$ values for MYB-expressing plants. Values normalized against average control $\Delta C$ t value for each gene. Values represent initial expression screening of leaf tissue and post-harvest expression results from young internode tissue and maturing internode tissue. NE: Normalized expression with standard error of the mean shown. Samples significantly different to the controls after ANOVA, $p=0.05$, are shown in bold. Control $n=3$. Plants are listed in ascending total lignin content for each line.

Additional file 4: Table S3. MYB-expressing sugarcane cell wall composition. The percentage of each component of the total composition is shown with the standard error of the mean. Samples significantly different to the controls after ANOVA followed by LSD test, $p=0.05$, are shown in bold. Control $n=3$. Plants are listed in ascending total lignin content for each line.

Additional file 5: Table S4. Glucose release by enzymatic hydrolysis. Glucose released into enzymatic hydrolysis solution $(\mathrm{mg} / \mathrm{mL})$ per gram $(\mathrm{g})$ of bagasse measured at six time points over $72 \mathrm{~h}$. The glucose released is shown with standard error of the mean. Samples significantly different to the control group after ANOVA followed by LSD test, $p=0.05$, are shown in bold. Control $n=3$.

Additional file 6: Table S5. Cellulose crystallinity index of MYB bagasse. $\mathrm{Cl}$ was calculated from the height ratio between the intensity of the crystalline peak $\left(\mathrm{I}_{002}-\mathrm{I}_{\mathrm{AM}}\right)$ and total intensity $\left(\mathrm{I}_{002}\right)$ after subtraction of the background signal.

Additional file 7: Table S6. Primers for ZmMYB cloning, genomic PCR and $\mathrm{APCR}$. Primers designed from GenBank accessions for PCR amplification of ZmMYB31 and ZmMYB42 genes from maize CDNA (1-4), for leaf gDNA screening from ZmMYB31 and ZmMYB42 gene cassettes (5-8) and $\mathrm{qPCR}$ quantification of MYB gene expression in young and maturing internodes (9-10).

Additional file 8: Table S7. Primers for qPCR of lignin biosynthetic genes.

\section{Abbreviations}

4CL: 4-coumarate CoA ligase; ANOVA: analysis of variance; $\mathrm{C} 3 \mathrm{H}$ : $p$-coumarate 3-hydroxylase; C4H: cinnamate 4-hydroxylase; CAD: cinnamyl alcohol dehydrogenase; CCOAOMT: caffeoyl-CoA O-methyltransferase; CCR: cinnamoyl CoA reductase; COMT: caffeic acid 3-O-methyl transferase; $\mathrm{F5}$ H: ferulate 5-hydroxylase; FPU: filter paper unit; G: guaiacyl lignin (unit); GFP: green fluorescent protein; H: p-hydroxyphenyl lignin (unit); HPIC: high-performance ion chromatography; HPLC: high-performance liquid chromatography; LSD: least significant difference; NOS: nopaline synthase; ORF: open reading frame; PAL: phenylalanine ammonia-lyase; PCR: polymerase chain reaction; $\mathrm{QPCR}$ : quantitative PCR; S: syringyl lignin (unit); UBI: ubiquitin; UTR: untranslated region.

\section{Authors' contributions}

CRP was involved in acquisition, analysis and interpretation of data, and crafting and critical revision of the manuscript. WPB made substantial contributions to experimental design, acquisition and interpretation of data, and crafting and critical revision of the manuscript. HDC made substantial contributions to conception, design, analysis and interpretation of data, and critical manuscript revision. WL and JR were responsible for the NMR compositional studies. All authors read and approved the final manuscript.

\section{Author details}

${ }^{1}$ Department of Biology, Syracuse University, Syracuse, NY 13244, USA.

${ }^{2}$ Center for Tropical Crops and Biocommodities, Queensland University 
of Technology, Brisbane, QLD 4000, Australia. ${ }^{3}$ US Department of Energy, Great Lakes Bioenergy Research Center (GLBRC), Wisconsin Energy Institute, University of Wisconsin, Madison, WI 53726, USA. ${ }^{4}$ Department of Biological System Engineering, University of Wisconsin, Madison, WI, USA. ${ }^{5}$ Department of Biochemistry, University of Wisconsin, Madison, WI 53726, USA.

\section{Competing interests}

The authors declare that they have no competing interests.

\section{Availability of data and material}

The datasets supporting the conclusions of this article are included within the article and its additional files.

\section{Funding}

This study was funded by the Australian Research Council Discovery Program (HDC; DP1093236) and the Sugar Research and Development Corporation (Sugar Research Australia) Scholarship Program (WPB; STU068). WL and JR were funded by the DOE Great Lakes Bioenergy Research Center (DOE BER Office of Science DE-FC02-07ER64494). The China Scholarship Council, State Education Department, supported living expenses for Wu Lan's PhD Program in the Department of Biological System Engineering, University of Wisconsin, Madison.

Received: 4 February 2016 Accepted: 30 June 2016

Published online: 15 July 2016

\section{References}

1. Waclawovsky AJ, Sato PM, Lembke CG, Moore PH, Souza GM. Sugarcane for bioenergy production: an assessment of yield and regulation of sucrose content. Plant Biotechnol J. 2010;8:263-76.

2. Taylor SH, Hulme SP, Rees M, Ripley BS, Woodward Fl, Osborne CP. Ecophysiological traits in C3 and C4 grasses: a phylogenetically controlled screening experiment. New Phytol. 2010;185:780-91.

3. Byrt CS, Grof CP, Furbank RT. C4 plants as biofuel feedstocks: optimising biomass production and feedstock quality from a lignocellulosic perspective. J Integr Plant Biol. 2011;53:120-35

4. Somerville C, Youngs H, Taylor C, Davis SC, Long SP. Feedstocks for lignocellulosic biofuels. Science. 2010:329:790-2.

5. Weng JK, Li X, Bonawitz ND, Chapple C. Emerging strategies of lignin engineering and degradation for cellulosic biofuel production. Curr Opin Biotechnol. 2008;19:166-72

6. Boerjan W, Ralph J, Baucher M. Lignin biosynthesis. Annu Rev Plant Biol. 2003;54:519-46.

7. Anterola AM, Lewis NG. Trends in lignin modification: a comprehensive analysis of the effects of genetic manipulations/mutations on lignification and vascular integrity. Phytochemistry. 2002;61:221-94.

8. Zhong R, Ye ZH. Transcriptional regulation of lignin biosynthesis. Plant Signal Behav. 2009:4:1028-34

9. Hatton D, Sablowski R, Yung MH, Smith C, Schuch W, Bevan M. Two classes of cis sequences contribute to tissue-specific expression of a PAL2 promoter in transgenic tobacco. Plant J. 1995:7:859-76.

10. Sonbol FM, Fornale S, Capellades M, Encina A, Tourino S, Torres JL, Rovira P, Ruel K, Puigdomenech P, Rigau J, Caparros-Ruiz D. The maize ZmMYB42 represses the phenylpropanoid pathway and affects the cell wall structure, composition and degradability in Arabidopsis thaliana. Plant Mol Biol. 2009;70:283-96.

11. Fornale S, Shi X, Chai $C$, Encina A, Irar S, Capellades M, Fuquet E, Torres $J$, Rovira P, Puigdomenech P, et al. ZmMYB31 directly represses maize lignin genes and redirects the phenylpropanoid metabolic flux. Plant J. 2010;64:633-44

12. Fornale S, Sonbol FM, Maes T, Capellades M, Puigdomenech P, Rigau J, Caparros-Ruiz D. Down-regulation of the maize and Arabidopsis thaliana caffeic acid O-methyl-transferase genes by two new maize R2R3-MYB transcription factors. Plant Mol Biol. 2006:62:809-23.

13. Masarin F, Gurpilhares DB, Baffa DC, Barbosa MH, Carvalho W, Ferraz A, Milagres AM. Chemical composition and enzymatic digestibility of sugarcane clones selected for varied lignin content. Biotechnol Biofuels. 2011:4:55.
14. Shen $H$, He X, Poovaiah CR, Wuddineh WA, Ma J, Mann DGJ, Wang H, Jackson L, Tang Y, Stewart CN, et al. Functional characterization of the switchgrass (Panicum virgatum) R2R3-MYB transcription factor PVMYB4 for improvement of lignocellulosic feedstocks. New Phytol. 2012;193:121-36.

15. Shen H, Poovaiah CR, Ziebell A, Tschaplinski TJ, Pattathil S, Gjersing E, Engle NL, Katahira R, Pu Y, Sykes R, et al. Enhanced characteristics of genetically modified switchgrass (Panicum virgatum L.) for high biofuel production. Biotechnol Biofuels. 2013;6:71

16. Du H, Feng BR, Yang SS, Huang YB, Tang YX. The R2R3-MYB transcription factor gene family in maize. PLOS ONE. 2012;7:e37463.

17. Mansfield SD, Kim H, Lu F, Ralph J. Whole plant cell wall characterization using solution-state 2D NMR. Nat Protoc. 2012;7:1579-89.

18. Lauvergeat $V$, Rech $P$, Jauneau A, Guez C, Coutos-Thevenot P, Grima-Pettenati J. The vascular expression pattern directed by the Eucalyptus gunnii cinnamyl alcohol dehydrogenase EgCAD2 promoter is conserved among woody and herbaceous plant species. Plant Mol Biol. 2002:50:497-509.

19. Patzlaff A, Newman LJ, Dubos C, Whetten R, Smith C, Mclnnis S, Bevan MW, Sederoff RR, Campbell MM. Characterisation of PtMYB1, an R2R3MYB from pine xylem. Plant Mol Biol. 2003;53:597-608.

20. Patzlaff A, Mclnnis S, Courtenay A, Surman C, Newman $L$, Smith C, Bevan MW, Mansfield S, Whetten RW, Sederoff RR, Campbell MM. Characterisation of a pine MYB that regulates lignification. Plant J. 2003:36:743-54.

21. Hughes TA. Regulation of gene expression by alternative untranslated regions. Trends Genet. 2006;22:119-22.

22. Mignone F, Gissi C, Liuni S, Pesole G. Untranslated regions of mRNAs. Genome Biol. 2002;3:1-10.

23. Pesole G, Mignone F, Gissi C, Grillo G, Licciulli F, Liuni S. Structural and functional features of eukaryotic mRNA untranslated regions. Gene. 2001:276:73-81.

24. Sharma AK, Sharma MK. Plants as bioreactors: recent developments and emerging opportunities. Biotechnol Adv. 2009;27:811-32.

25. Wilkie GS, Dickson KS, Gray NK. Regulation of mRNA translation by $5^{\prime}$ - and 3'-UTR-binding factors. Trends Biochem Sci. 2003;28:182-8.

26. Koziel MG, Carozzi NB, Desai N. Optimizing expression of transgenes with an emphasis on post-transcriptional events. In: Filipowicz W, Hohn T, editors. Post-transcriptional control of gene expression in plants. Dordrecht: Springer; 1996. p. 393-405.

27. Omer S, Kumar S, Khan BM. Over-expression of a subgroup 4 R2R3 type MYB transcription factor gene from Leucaena leucocephala reduces lignin content in transgenic tobacco. Plant Cell Rep. 2013;32:161-71.

28. Zhu L, Shan H, Chen S, Jiang J, Gu C, Zhou G, Chen Y, Song A, Chen F. The heterologous expression of the crysanthemum R2R3-MYB transcription factor alters lignin composition and represses flavonoid synthesis in Arabidopsis thaliana. PLOS ONE. 2013:8:e65680.

29. Grivet L, Arruda P. Sugarcane genomics: depicting the complex genome of an important tropical crop. Curr Opin Plant Biol. 2002;5:122-7.

30. Meyer P. Variation of transgene expression in plants. Euphytica. 1995;85:359-66.

31. Lan W, Morreel K, Lu F, Rencoret J, del Rio JC, Voorend W, Vermerris W, Boerjan W, Ralph J. Maize tricin-oligolignol metabolites and their implications for monocot lignification. Plant Physiol. 2016. doi:10.1104/ pp.16.02012.

32. Lan W, Lu F, Regner M, Zhu Y, Rencoret J, Ralph SA, Zakai UI, Morreel K, Boerjan W, Ralph J. Tricin, a flavonoid monomer in monocot lignification. Plant Physiol. 2015;167:1284-95.

33. Del Río JC, Rencoret J, Prinsen P, Martínez AT, Ralph J, Gutiérrez A. Structural characterization of wheat straw lignin as revealed by analytical pyrolysis, 2D-NMR, and reductive cleavage methods. J Agric Food Chem. 2012:60:5922-35.

34. Ralph J. Hydroxycinnamates in lignification. Phytochem Rev. 2010;9:65-83.

35. Del Río JC, Lino AG, Colodette JL, Lima CF, Gutiérrez A, Martínez ÁT, Lu F, Ralph J, Rencoret J. Differences in the chemical structure of the lignins from sugarcane bagasse and straw. Biomass Bioenerg. 2015;81:322-38.

36. Benjamin Y, Cheng H, Gorgens JF. Evaluation of bagasse from different varieties of sugarcane by dilute acid pretreatment and enzymatic hydrolysis. Ind Crops Prod. 2013;51:7-18.

37. Benjamin Y, Gorgens JF, Joshi SV. Comparison of chemical composition and calculated ethanol yields of sugarcane varieties harvested for two growing seasons. Ind Crops Prod. 2014;58:133-41. 
38. Jung JH, Vermerris W, Gallo M, Fedenko JR, Erickson JE, Altpeter F. RNA interference suppression of lignin biosynthesis increases fermentable sugar yields for biofuel production from field-grown sugarcane. Plant Biotechnol J. 2013;11:709-16.

39. Jung JH, Fouad WM, Vermerris W, Gallo M, Altpeter F. RNAi suppression of lignin biosynthesis in sugarcane reduces recalcitrance for biofuel production from lignocellulosic biomass. Plant Biotechnol J. 2012;10:1067-76.

40. Xu B, Escamilla-Trevino LL, Sathitsuksanoh N, Shen Z, Shen H, Zhang YH, Dixon RA, Zhao B. Silencing of 4-coumarate:coenzyme A ligase in switchgrass leads to reduced lignin content and improved fermentable sugar yields for biofuel production. New Phytol. 2011;192:611-25.

41. Fornale S, Capellades M, Encina A, Wang K, Irar S, Lapierre C, Ruel K, Joseleau JP, Berenguer J, Puigdomenech P, et al. Altered lignin biosynthesis improves cellulosic bioethanol production in transgenic maize plants down-regulated for cinnamyl alcohol dehydrogenase. Mol Plant. 2012:5:817-30.

42. Schell DJ, Farmer J, Newman M, McMillan JD. Dilute-sulfuric acid pretreatment of corn stover in pilot-scale reactor: investigation of yields, kinetics, and enzymatic digestibilities of solids. Appl Biochem Biotechnol. 2003;105-108:69-85.

43. Silverstein RA, Chen Y, Sharma-Shivappa RR, Boyette MD, Osborne J. A comparison of chemical pretreatment methods for improving saccharification of cotton stalks. Bioresour Technol. 2007;98:3000-11.

44. Legay S, Sivadon P, Blervacq AS, Pavy N, Baghdady A, Tremblay L, Levasseur C, Ladouce N, Lapierre C, Seguin A, et al. EgMYB1, an R2R3 MYB transcription factor from eucalyptus negatively regulates secondary cell wall formation in Arabidopsis and poplar. New Phytol. 2010;188:774-86.

45. Tamagnone L, Merida A, Parr A, Mackay S, Culianez-Macia FA, Roberts K, Martin C. The AmMYB308 and AmMYB330 transcription factors from antirrhinum regulate phenylpropanoid and lignin biosynthesis in transgenic tobacco. Plant Cell. 1998;10:135-54.

46. Baxter HL, Stewart CN. Effects of altered lignin biosynthesis on phenylpropanoid metabolism and plant stress. Biofuels. 2013:4:635-50.

47. Vanholme R, Demedts B, Morreel K, Ralph J, Boerjan W. Lignin biosynthesis and structure. Plant Physiol. 2010;153:895-905.

48. Christensen AH, Quail PH. Ubiquitin promoter-based vectors for highlevel expression of selectable and/or screenable marker genes in monocotyledonous plants. Transgenic Res. 1996;5:213-8.

49. Christensen AH, Sharrock RA, Quail PH. Maize polyubiquitin genes: structure, thermal perturbation of expression and transcript splicing, and promoter activity following transfer to protoplasts by electroporation. Plant Mol Biol. 1992;18:675-89.

50. Bevan M, Barnes WM, Chilton MD. Struture and transcription of the nopaline synthase gene region of T-DNA. Nucleic Acids Res. 1983;11:369-85.

51. Bower R, Elliott AR, Potier BAM, Birch RG. High-efficiency, microprojectilemediated cotransformation of sugarcane, using visible or selectable markers. Mol Breed. 1996;2:239-49.

52. Thomson D, Henry R. Single-step protocol for preparation of plant tissue for analysis by PCR. Biotechniques. 1995;19:394-400.
53. Sambrook J, Russell D. Molecular cloning: a laboratory manual. New York: Cold Spring Harbor Laboratory; 2001.

54. Pan YH, Michael TP, Hudson ME, Kay SA, Chory J, Schuler MA. Cytochrome P450 monooxygenases as reporters for circadian-regulated pathways. Plant Physiol. 2009;150:858-78.

55. Rogers LA, Dubos C, Cullis IF, Surman C, Poole M, Willment J, Mansfield $\mathrm{SD}$, Campbell MM. Light, the circadian clock, and sugar perception in the control of lignin biosynthesis. J Exp Bot. 2005;56:1651-63.

56. van Dillewijn C. Botany of sugarcane. Chronica Botanica Co.; 1952.

57. Hames B, Ruiz R, Scarlata C, Sluiter A, Sluiter J, Templeton D. Preparation of samples for compositional analysis: laboratory analytical procedure (LAP). National Renewable Energy Laboratory. 2008; Technical report: NREL/ TP-510-42620.

58. Sluiter A, Hames B, Ruiz R, Scarlata C, Sluiter J, Templeton D, Crocker D. Determination of structural carbohydrates and lignin in biomass: laboratory analytical procedure (LAP). National Renewable Energy Laboratory. 2008; Technical report: NREL/TP-510-42618.

59. Sluiter A, Hames B, Hyman D, Payne C, Ruiz R, Scarlata C, Sluiter J, Templeton D, Wolfe J. Determination of total solids in biomass and total dissolved solids in liquid process samples: laboratory analytical procedure (LAP). National Renewable Energy Laboratory. 2008; Technical report: NREL/TP-510-42621.

60. Adney B, Baker J. Measurement of cellulase activities: laboratory analytical procedure (LAP). National Renewable Energy Laboratory. 2008; Technical report: NREL/TP-510-42628.

61. Bradford MM. A rapid and sensitive method for the quantitation of microgram quantities of protein utilizing the principle of protein-dye binding. Anal Biochem. 1976;72:248-54.

62. Harrison MD, Zhang Z, Shand K, O'Hara IM, Doherty WO, Dale JL. Effect of pretreatment on saccharification of sugarcane bagasse by complex and simple enzyme mixtures. Bioresour Technol. 2013;148:105-13.

63. Segal L, Creely JJ, Martin AE, Conrad CM. An empirical method for estimating the degree of crystallinity of native cellulose using the $\mathrm{X}$-ray diffractometer. Text Res J. 1959;29:786-94.

64. Inman-Bamber NG, Bonnett GD, Spillman MF, Hewitt ML, Jackson J. Increasing sucrose accumulation in sugarcane by manipulating leaf extension and photosynthesis with irrigation. Aust J Agric Res. 2008;59:13.

65. Kim H, Ralph J, Akiyama T. Solution-state 2D NMR of Ball-milled plant cell wall gels in DMSO-d 6. Bioenerg Res. 2008;1:56-66.

66. Kim H, Ralph J. Solution-state 2D NMR of ball-milled plant cell wall gels in DMSO-d6/pyridine-d5. Org Biomol Chem. 2010;8:576-91.

67. Kim H, Ralph J. A gel-state 2D-NMR method for plant cell wall profiling and analysis: a model study with the amorphous cellulose and xylan from ball-milled cotton linters. Rsc Adv. 2014:4:7549-60.

\section{Submit your next manuscript to BioMed Central and we will help you at every step:}

- We accept pre-submission inquiries

- Our selector tool helps you to find the most relevant journal

- We provide round the clock customer support

- Convenient online submission

- Thorough peer review

- Inclusion in PubMed and all major indexing services

- Maximum visibility for your research

Submit your manuscript at www.biomedcentral.com/submit
BioMed Central 